\title{
Huellas pedagógicas alemanas en España Una aproximación histórica
}

\author{
JuLIO Mateos MoNTERo
}

Universidad de Salamanca

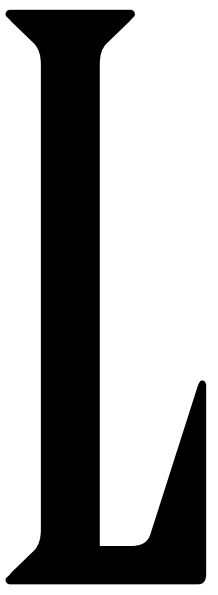

as influencias pedagógicas en España procedentes de aquellos países europeos que habían emprendido con anterioridad (y con más decisión) la construcción de sus sistemas nacionales de enseñanza, han sido variables en el tiempo y su preeminencia se ha desplazado de unos países a otros. A partir de los años sesenta del pasado siglo el peso de las ciencias de la educación anglosajonas, de carácter más empírico, marcaron una hegemonía de los discursos tecnicistas (aunque éstos ya hubieran comenzado a hacerse notar con anterioridad). La influencia francesa fue siempre importante, pero conoce su mejor momento entre principios de los cincuenta y mediados de los setenta, lo cual no es ajeno a la implantación del francés como segundo idioma en nuestro sistema educativo. Y si damos valor indicativo a la estadística de las traducciones pedagógicas al español, en ese mismo periodo, los textos alemanes descienden del $25 \%$ al $10,6 \%$, pues el mayor influjo germánico se sitúa más en la primera mitad del siglo XX y, aún más atrás, en la incipiente pedagogía decimonónica. Como no se trata aquí de distraernos lo más mínimo en las influencias educativas del mundo occidental, iré directamente a cumplir con el motivo de estas páginas: el influjo alemán en España y algunos cauces de su importación ${ }^{1}$.

Frecuentemente en la literatura hispana sobre educación se ha usado el término de 'germánico' bajo la acepción de «relativo a Alemania». Para mayor concreción, por 'lo germánico' se entendería aquí el ámbito de implantación de la lengua alemana y los tiempos posteriores a la construcción del Estado moderno alemán. En cualquier caso, tratándose del específico mundo de la educación y la cultura hay que salvar las fronteras políticas de Europa que tantos cambios han sufrido a lo largo de su convulsa historia y, ocasionalmente, los límites temporales. En términos de cultura pedagógica ¿Cómo no considerar incluida en lo alemán la seminal obra de Comenio, por mucho que este universal personaje reivindicara la lengua materna (el checo) y viviese en el siglo XVII? ¿O el caso del suizo Pestalozzi? ¿Y qué decir del mismo Rudolf Steiner, nacido en la actual Croacia? Estos y otros pedagogos se sitúan en el mismo ámbito cultural-lingüístico que figuras cimeras 'genuinamente' alemanas como Fröbel, Herbart, Kerschensteiner o Natorp, cuyos nombres han ido compareciendo con fuerza en la literatura hispana sobre educación.

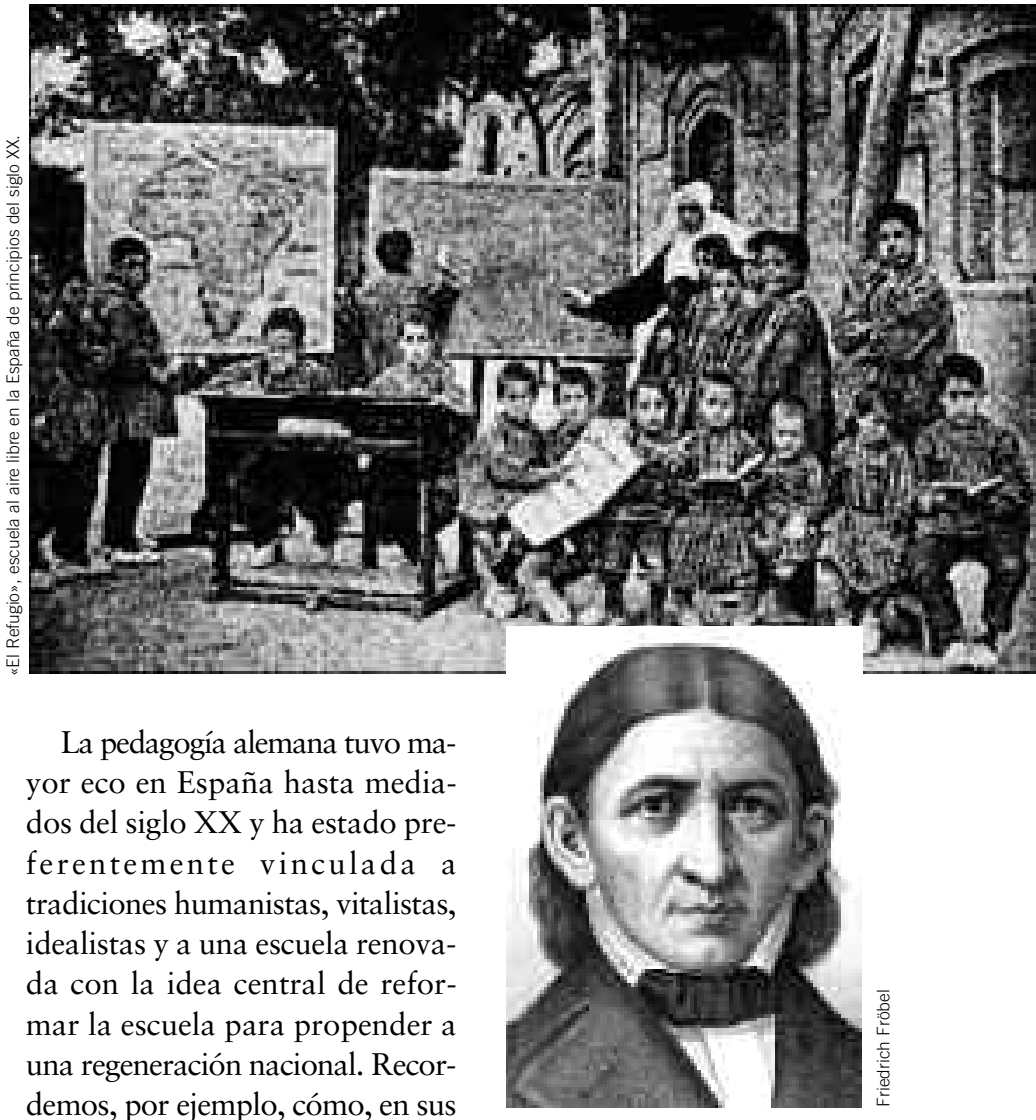
famosos Discursos a la nación alemana (1807-1808), J. G. Fichte, imbuido de fervor pestalozziano, se proponía exponer «la manera de regenerar nuestra nacionalidad merced a una educación nueva...»(Fichte 1899) ${ }^{2}$. ¿Por qué introduzco aquí esta referencia? Porque creo que aquella corriente de educación patriótica, preñada de idealismo, junto a ideas del reformismo pedagógico como la intuición y la visión global del entorno próximo al niño, formó en la cultura alemana una potentísima tradición discursiva que, a mi juicio, ha sido la influencia que ha dejado huella más nítida en la teoría y práctica escolar hispanas. Se trata, concretamente, de la tradición discursiva que dio lugar a la Heimatkunde que, junto a otros componentes y a lo largo de una laberíntica historia, en España acabó cristalizando en una asignatura de la actual Educación Primaria: el Conocimiento del Medio, Natural, 


\section{Resumen}

Las influencias pedagógicas alemanas en España, como todo, tienen su historia -que es compleja-y de la cual hay estudios que recogen abundantes datos y hechos contrastados. En el acotado espacio de este trabajo, más que aportar información novedosa sobre el tema, se hace una aproximación general, de largo recorrido, con interpretaciones del autor que pretenden dar un sentido complementario a las más usuales que se ocupan de coyunturas y periodos concretos.

Palabras clave: pedagogía, educación, historia de la ciencia

\begin{abstract}
Die pädagogischen Einflüsse, die Spanien aus dem deutschsprachigen Raum erhalten hat, können bei all ihrer Komplexität gleichwohl auf eine lange und wohldokumentierte Geschichte zurückblicken. In dieser Arbeit möchten wir weniger neue Tatsachen ans Licht holen als vielmehr einen weit reichenden Rück- und Überblick anbieten, der über einzelne, konkreten Perioden und Begebenheiten gewidmete Arbeiten hinausgeht und diese interpretativ in einen großen Zusammenhang setzt.
\end{abstract}

Schlüsselwörter: Pädagogik, Bildung und Erziehung, Wissenschaftsgeschichte

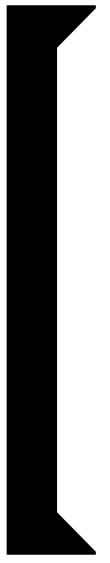

La pedagogía alemana tuvo mayor eco en España hasta mediados del siglo XX y ha estado preferentemente vinculada a tradiciones humanistas, vitalistas, idealistas y a una escuela renovada con la idea central de reformar la escuela para propender a una regeneración macional.

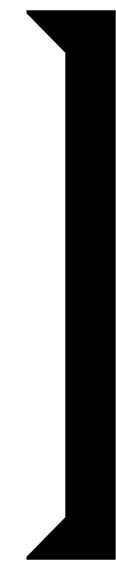

Social y Cultural. La importancia de esa tradición cultural y didáctica va más allá de una particular materia escolar y por ello le dedicaré algunas líneas más adelante ${ }^{3}$. Procedamos con cierto orden cronológico.

\section{Ecos germánicos en la primera cultura pedagógica hispana}

La primera influencia clara proviene de Pestalozzi. Antes de las guerras napoleónicas, cuando aún no se habían puesto los cimientos legislativos generales para un sistema de enseñanza, había en España una minoría ilustrada que se interesaba por la educación y puso cierto interés en importar métodos pedagógicos que lucían como eficaces novedades en Europa. Ello dio lugar a la creación del Real Instituto Militar Pestalozziano, que tuvo una fugaz existencia al amparo de Manuel Godoy (1806-1808). Pero el experimento fue de carácter elitista, cortesano, concebido para proyectar una imagen del Principe de la Paz en Europa a través del entramado de relaciones diplomáticas. Tanto los alumnos (hijos de familias pudientes) como los maestros que en el Instituto se formaban como observadores (militares, clérigos y personas de cierta alcurnia que obtenían la exclusiva de poder enseñar según el método de Pestalozzi) no se podrían confundir con la "gran muchedumbre» a la que las Memorias de Godoy se refieren como objeto de su experimento pestalozziano. El Instituto, circunscrito a medios militares, aislado de las escuelas populares, no puede considerarse una vía de introducción eficiente de la pedagogía del suizo en España. Pero la propaganda que entonces se generó dejó un depósito que posteriormente fue aprovechado por los reformadores del liberalismo hispano.
Al margen de la nula incidencia del Instituto Pestalozziano en escuelas populares españolas, su breve existencia es interesante porque fue acompañada de tres circunstancias que, premonitoriamente, se han manifestado de forma recurrente. La primera es que las ideas reformistas que fueron concebidas para la educación popular, cuando adquieren cierto renombre en

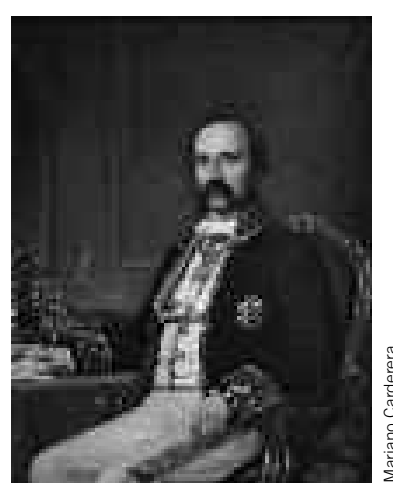
el imaginario del progreso modernizador, son acaparadas por facciones y sectores de grupos sociales emergentes, y transformadas en orientaciones para la educación de sus propios hijos en instituciones de vanguardia ${ }^{4}$. La segunda circunstancia es que una y otra vez se han buscado fuera de España las innovaciones, las teorías y los métodos de moda y se han presentado con la aureola del progreso. Y una tercera circunstancia, que también se hizo visible con motivo del tempranero experimento pestalozziano, fue el rechazo que reiteradamente suscitaron los aires foráneos de la modernización pedagógica por distintas causas. Unas veces porque los sectores eclesiales se opusieron con firmeza a lo que consideraban heterodoxia religioso-educativa ${ }^{5}$. Otras veces la exaltación de los valores nacionales en España rechazaron «las modas extranjeras» por motivos escasamente racionales, de estúpido orgullo, lo cual podía coincidir (o no) con aquellos que con espíritu crítico reaccionaban contra el papanatismo que también despertaban las ideas importadas.

En el siglo XIX se creó el sistema educativo español y durante dicho siglo se mantuvo un desarrollo lento y misérrimo de la escuela primaria, atrasada en todos los aspectos y, desde luego, también en ideas ajenas a la experiencia artesanal del maestro. Los primeros maestros de la 'Escuela Normal', dedicada a la formación de profesores, algunos de los cuales alcanzaron notable prestigio, como Pablo Montesino (1781-1849), Mariano Carderera (1815-1893) o Joaquín Avendaño (1816-1887), crearon la primera cultura pedagógica en España, por el procedimiento de recoger, glosar o, simplemente, copiar textos de autores extranjeros. Ellos no ignoraban que fue en el Estado prusiano de Federico II, en el siglo XVIII, donde se erigió por primera vez una escuela nacional obligatoria y gratuita y que 
es en el II. Reich, bajo el autoritarismo de Bismarck, cuando se pusieron en marcha medidas precursoras de lo que conocemos como Estado social que llevaron a crear el sistema escolar más sólido en la Europa del momento. Por ello, Carderera (1882: 308) afirma que: "La enseñanza obligatoria nació en los países del Norte, gobernados por ordenanzas militares, y llegó á prosperar merced a la idea religiosa». En los textos de estos normalistas ya aparecen los pedagogos alemanes más relevantes, pues no en vano en el mismo prólogo de su gran diccionario, Carderera escribe que «tenemos algún conocimiento de la literatura pedagógica alemana, fuente de donde se deriva la de todos los países; hemos conferenciado sobre el particular con los directores y maestros de establecimientos célebres en Alemania y Suiza; contamos con la colaboración de algunos de ellos;...” (Carderera 1954). Recogieron las aportaciones de «los más grandes» (Pestalozzi, Fröbel, Herbart,...). También de personajes que hoy "suenan» menos, pero que en su época impulsaron la escuela pública, como es el caso de Friedrich Diesterweg (17901866) cuya memoria continuó en textos de otros autores españoles del siglo XX o el de H. A. Niemeyer, el cual hubo de inventar no pocas orientaciones pedagógicas y organizativas destinadas a erigir una escuela alemana. De unos y otros la cultura normalista española extrajo principios canónicos que han perdurado prácticamente hasta el presente, como el ya citado de la intuición, el de graduar las enseñanzas conforme a leyes naturales y el «natural» desarrollo de la mente infantil, el desarrollo «integral» del escolar en las dimensiones religiosa, moral, física e intelectual, etc.. En fin, elementos que han sido importantes pilares didácticos. Puede añadirse que se ocuparon también de traducir, al menos con el afán de estar al día como ejemplares formadores de maestros, propuestas prácticas muy avanzadas y dispuestas para ser aplicadas ${ }^{6}$.

Pero no extraigamos una visión demasiado optimista. Aquellas ideas y textos importados de Alemania no fueron más que papel sin encarnación en las míseras escuelas decimonónicas. $\mathrm{Ni} \mathrm{Pa}$ blo Montesino, ni sus discípulos Carderera o Avendaño (por no citar otros) creían en la posibilidad real de innovación didáctica alguna en los páramos escolares de España. Sus preocupaciones eran fundamentalmente organizativas: cuadros horarios, procurar agrupaciones posibles y la necesaria disciplina, poner orden donde había caos y la intendencia y posibilidades de una escuela para la cual el Estado no había dispuesto los recursos económicos más primarios.

Hay que esperar a finales del si- glo XIX para ver cómo se cuestiona fuertemente la educación tradicional y elitista por la Institución Libre de Enseñanza (ILE) y se apuesta más decididamente por regenerar el país a través de la escuela. De esa crisis que enfrenta a los «viejos pedagogos» con los jóvenes intelectuales institucionistas ${ }^{7}$, surge todo un movimiento liberal-progresista que abrirá las puertas a la mayor influencia de la pedagogía alemana en España durante lo que se ha llamado la edad de plata de la cultura española (1900-1936).

Aún en el siglo XIX es la pedagogía de Friedrich Fröbel la que se presenta como expresión más acabada de métodos dignos de ser emulados, y su introducción en España es capitaneada por Pedro de Alcántara García, amigo de la ILE (recordemos que tanto Fröbel, como la misma ILE encontraron inspiración filosófica en Krause), el cual hizo una importante labor difusora en la revista La Escuela Moderna de los Kindergarten. De esa inspiración se derivaron prácticas escolares concretas como el excursionismo, a lo cual Pedro de Alcántara unía la tradición de las lecciones de cosas (fértil y universal modalidad metodológica que resultó de una feliz conjunción de educadores germánicos y anglosajones) y una especial preocupación por la educación de la mujer ${ }^{8}$. Para no extenderme demasiado valga decir que se llegó incluso, en 1876, a la creación, por Real Decreto, de un Kindergarten construido en edificio de nueva planta y vinculado a la Escuela Normal Central de Madrid, siendo D. Pedro de Alcántara el artífice aunque su dirección de la institución corriese a cargo de Eugenio Bartolomé y Mingo. De este episodio puede encontrarse amplia información (Colmenar 1989; Molero 2001).

\section{Alemania en la edad dorada de la pedagogía española}

Como indiqué al principio, no trato tanto de presentar noticias originales sobre la proyección pedagógica de Alemania en España, sino de aportar algunas interpretaciones globales sobre el tema. Para obtener esa visión hay que introducirse ya en la efervescencia educativa que en España refleja lo que en el primer tercio del siglo XX (podemos decir que desde 1900 a 1936) aparece como movimiento de renovación pedagógica del «uno al otro confín», en todos los países donde se ha establecido un sistema nacional de enseñanza. Ortega y Gasset y su discípulo Lorenzo Luzuriaga son la pareja representativa, con distintas funciones y rasgos ideológicos, ¿ de esta nueva etapa 
para la influencia de la pedagogía alemana en España bien distinta a la del siglo XIX. De alguna manera, ellos y sus amigos, flor y nata de las «clases de la cultura", hicieron también el puente y transición de los "clásicos» alemanes a los pedagogos de su propio tiempo, de la revolución pedagógica propia del primer tercio del siglo $\mathrm{XX}^{9}$. Se trata, en efecto de otra etapa, la más fecunda para la proyección alemana en el mundo educativo hispano. Con la 'Escuela Nueva' y análogos movimientos societarios se internacionalizó una comunicación en la que participaban, entre otros países, España y Alemania. Mediante pu-

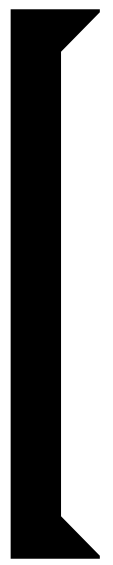

\section{Lorenzo Luzuriaga fue traductor al castellano de Pestalozzi, Kant, Goethe,Herbart,Kerschensteiner y Dithey, entre otros. Pero no esturo solo en la ta- reade poner adisposición del público hispano las obras de pedagogos germánicos. Mã. de Maeztu traduce a Natorp, Domingo Barnés a W. Rein y Jo- séGaos a E.Spranger,posiblemente uno del los pe- dagogos más lé́dos en tiempos de la II República y, después, en los de la dictadura.}

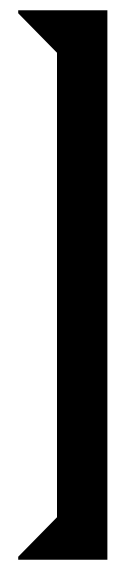

blicaciones asequibles a una buena parte del magisterio que en ese periodo avanzó en su profesionalización y formación, los ecos del reformismo escolar germánico llegaron a España, pero ocupando una determinada posición de superioridad simbólica en la distribución del conocimiento, como expondré de inmediato.

En 1907 se creó la Junta de Ampliación de Estudios (JAE) a la que se ha atribuido una principalísima función en la importación de diversas novedades científicas por aquellos pensionados que visitaban Europa para recoger una simiente que, supuestamente, daría una cosecha de progreso y modernización para España. La Pedagogía fue, como es sabido, uno de los saberes que recabaron una especial atención de la JAE. Entre 1907 y 1936, unos 410 educadores (inspectores, maestros, directores de graduadas, normalistas, profesores de segunda enseñanza y de universidad) gozaron de distintas modalidades de pensión para ir al extranjero y, aunque es cierto que Alemania como país de destino se situó detrás de Francia, Bélgica y Suiza ${ }^{10}$, los viajeros que eligieron aquel país eran personajes muy cualificados e influyentes en España. Digamos que era la élite del saber-poder pedagógico de la época, caracterización que viene muy ajustada al caso, si atendemos a cierto ethos y posición intelectual del más insigne de sus mentores: el pensador germanófilo Ortega y Gasset. No es casualidad que los educadores que viajaron a Alemania lo hicieran a sus universidades, a estudiar la alta pedagogía teórica. Esos centros estaban prácticamente vetados a los "sencillos maestros», por falta de preparación, por desconocimiento del idioma y, en fin, porque todo el ambiente (el «natural ser de las cosas») les conducía a visitar escuelas modelo de Fran- cia o Bélgica; es decir: a ocuparse de cuestiones prácticas, técnicas, métodos; a conocer de primera mano un saber práctico que, por supuesto, siempre ha ocupado un lugar subordinado respecto al conocimiento teórico con el que se identificaba la académica pedagogía alemana. La jerarquía era palmaria. No hay más que ver una muestra de los personajes que fueron a Alemania por cuenta de la JAE: Manuel Alonso Zapata, José Castillejo Duarte, M. Bartolomé Cossío, Federico Doreste, Luis García Sainz, Luis de Hoyos, Lorenzo Luzuriaga, Juan Llongueras, Angel Llorca, María de Meztu Whitney, Antonio J. Onieva, José Ontañón, Fernando de los Ríos, Pedro Roselló, Ma Pilar Oñate, Josefina Sela Sampil, María Soriano Llorente, Vicente Viqueira,... Naturalmente, también otros y otras muy notables educadores ampliaron sus estudios en otros países, pero la proporción de pensionados de «reconocido prestigio» más alta se dio en el destino alemán. Conviene especificar que la mayor parte hicieron el viaje antes de la guerra de 1914. Después, la preeminencia de aliadófilos en los ambientes próximos a la JAE hizo decaer la demanda, por mu-

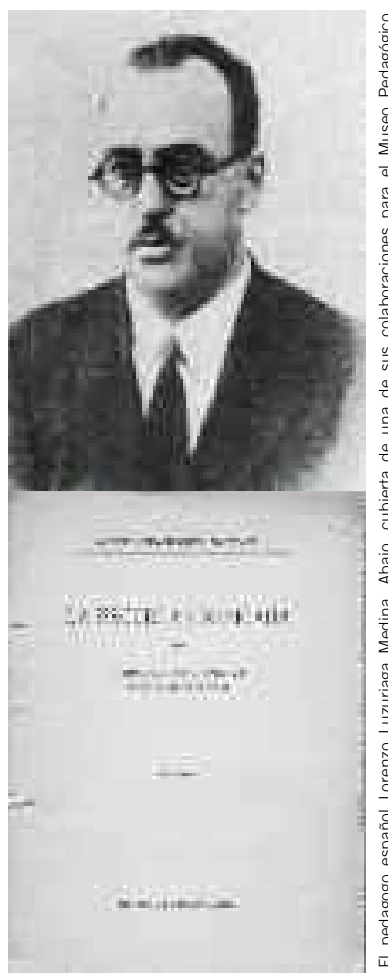
cho que Luzuriaga intentase hacer ver la pluralidad y el liberalismo presente en la pedagogía alemana (Marín Eced 1990: 250).

Las universidades alemanas más atrayentes para los españoles fueron: la de Jena, donde enseñaba W. Rein, el más conocido seguidor de Herbart, y P. Petersen; la de Leipzig en la cual W. Wundt había creado el primer laboratorio de psicología experimental tiempo atrás y donde también trabajaba E. Spranger, y la de Marburgo donde estaba el origen de la pedagogía social de Paul Natorp. También las universidades de Heidelberg, donde estaba E. Krieck, y de Munich en la cual G. Kerschensteiner hacía apostolado por su escuela del trabajo. La visita de varios españoles a Marburgo dio lugar a un conocimiento mutuo de los que se llamarían los «marburgianos»y que llegarían a formar parte de la llamada "generación de 1914» ${ }^{11}$. Todos ellos son destacadas personalidades de la cultura pedagógica académica y/o de la cultura a secas; cargos públicos en tiempos de la II República y definitivamente consagrados en la historia de la intelligentsia española del periodo al que nos referimos.

Lorenzo Luzuriaga fue traductor al castellano de Pestalozzi, Kant, Goethe, Herbart, Kerschensteiner y Dilthey, entre otros. Pero no estuvo solo en la tarea de poner a disposición del público hispano las obras de pedagogos germánicos. $\mathrm{M}^{\mathrm{a}}$. de Maeztu traduce a Natorp, Domingo Barnés a W. Rein y José Gaos (amigo del grupo) a E. Spranger, posiblemente uno de los pe- 
dagogos más leídos en tiempos de la II República y, después, en los de la dictadura. La relación puede extenderse mucho. Lo que interesa destacar es que nos encontramos con un amplio grupo de intelectuales muy capaces, con estrechas relaciones de amistad e incluso familiares, que disponían de instituciones y medios oficiales y privados para impulsar un proyecto educativo muy consciente y definido. No era, por tanto, una conjunción fortuita de algunos cultos normalistas, como en el siglo XIX.

\section{Plataformas editoriales}

Detallemos un poco más. Sin duda, fueron la Revista de Pedagogía y su director, Lorenzo Luzuriaga, los cauces más eficaces para la importación y difusión de las ideas y realizaciones educativas alemanas ${ }^{12}$. Aunque la publicación y el personaje sean harto conocidos para los historiadores de la educación, tal vez convenga decir aquí algo sobre ellos. La Revista de Pedagogía fue durante su existencia (1922-1936) el órgano difusor de la Liga Internacional de la Educación Nueva. Con ella se buscaba modernizar la escuela española, abriendo puertas a la mejor producción pedagógica del extranjero, a modelos de organización escolar y experiencias didácticas ${ }^{13}$. Los impulsores de la Revista de Pedagogía, con Luzuriaga a la cabeza, representaban la corriente liberal y socialista, imbuidos fuertemente por la ILE, son importantes artífices del modelo educativo republicano. Pueden contarse hasta treinta y nueve reseñas de obras alemanas que firma Luzuriaga en la Revista de Pedagogía. Dio así a conocer trabajos de A. Messer (en su faceta de historiador de la educación), de P. Oestreich (compañero ideológico de Luzuriaga en Alemania), de E. Meumann (fundador de la pe-

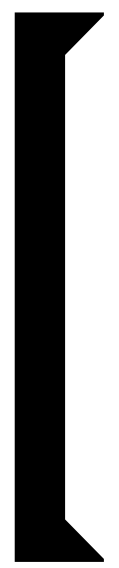

Cabe mencionar el ejemplo del voluminoso Diccionario de Pedagogía Labor (Barcelona, 1936)

que dirigiera Luis Sánchez Sarto. Entre sus casi mil entradas figura una exhaustiva relación de autores germánicos, amén de conceptos, experiencias, modelos organizativos o instituciones del mismo origen.

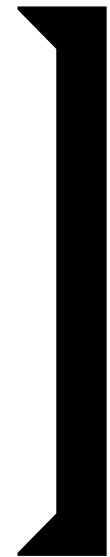

dagogía experimental, discípulo de Wundt), de P. Petersen (difusor del plan de Jena), de Ernst Krieck (el más reconocido pedagogo militante del nazismo), de W. Dilthey (en reflexiones del afamado filósofo), o de G. Giese (difusor de la política educativa del nacionalsocialismo), para citar sólo unos ejemplos. La labor divulgadora no quedó ahí, pues las mismas páginas de Revista de Pedagogía acogieron traducciones de bastantes de esos autores y otros de gran fama como G. Kerschensteiner, E. Spranger, W. A. Lay o el radical G. Wineken. Cabría añadir, que la línea editorial de la misma Revista de Pedagogía publi- có aún otras obras y fueron reeditadas por Luzuriaga desde su exilio de Argentina, en la editorial Losada.

Por otra parte, la editorial Labor fue también importante cauce de difusión para autores alemanes en España ${ }^{14}$. Cabe mencionar el ejemplo del voluminoso Diccionario de Pedagogía Labor (Barcelona, 1936) que dirigiera Luis Sánchez Sarto. Entre sus casi mil entradas figura una exhaustiva relación de autores germánicos, amén de conceptos, experiencias, modelos organizativos o instituciones del mismo origen. No es casualidad que el Diccionario se publicara primero en alemán al contar la ca-
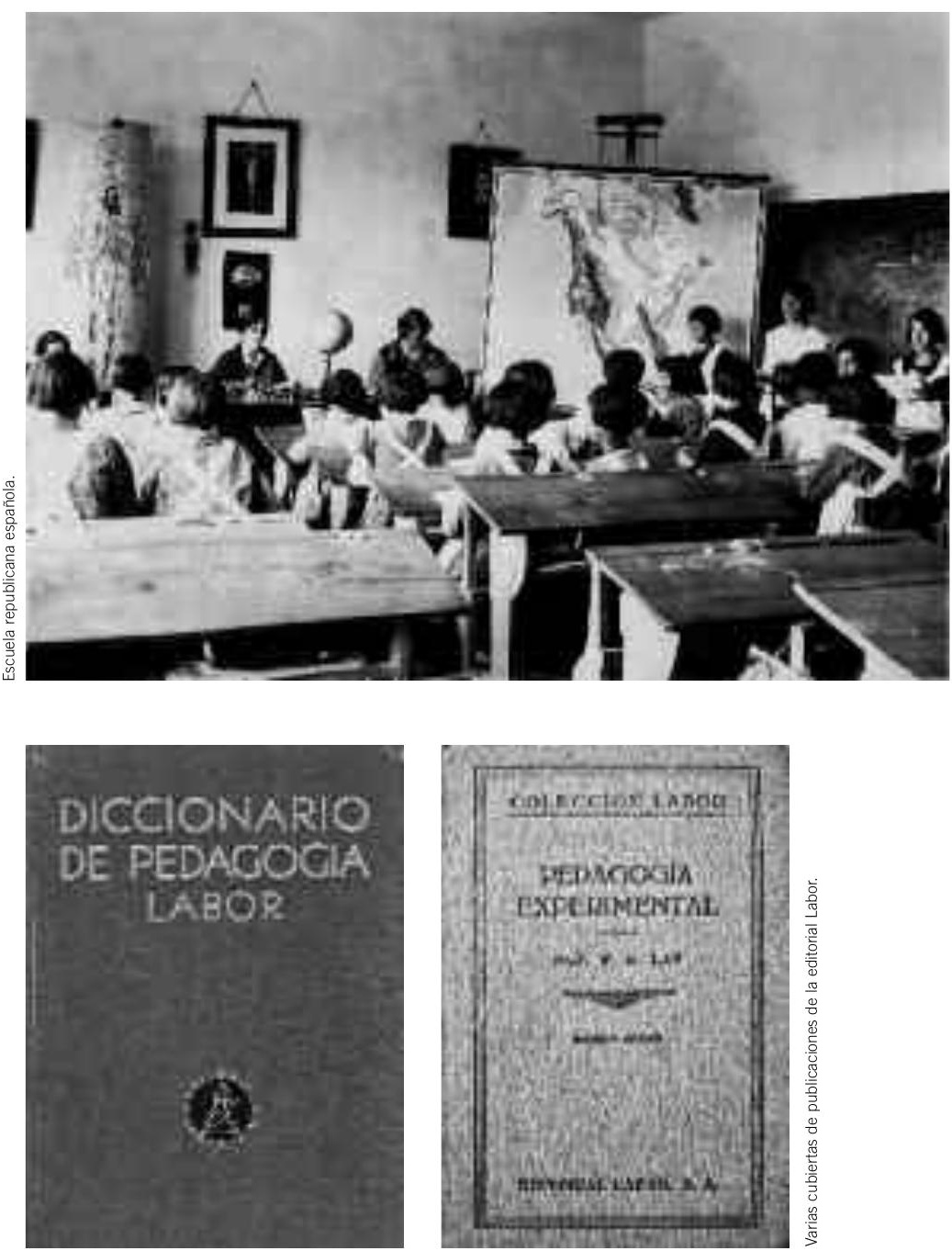

sa Labor con una amplia plantilla de colaboradores en Alemania y otra en España de cualificados traductores especialistas en distintas materias pedagógicas. En la gruesa edición española se abordaba la instrucción pública en Alemania del momento y, siendo la tendencia general de la obra más bien conservadora, el tono es muy complaciente con el proyecto educativo del Dritten Reich. En cualquier caso resulta bastante arriesgado interpretar con esquemas del presente las relaciones entre política y pedagogía de aquellos años, por lo que creo conveniente decir unas palabras al respecto. 


\section{El riesgo de clasificar}

El régimen nacionalsocialista gobernó Alemania desde 1933 a 1945 y en España esos años coinciden con la II República, la guerra y el primer franquismo. Tan convulsos tiempos (lo fueron a escala mundial) conmovieron profundamente el mundo educativo y, por supuesto, la transferencia de modelos e ideas entre ambos países. Por su amplitud y complejidad es impensable tratar aquí el tema. Sin embargo ha de advertirse que son demasiado frecuentes las simplificaciones que actualmente ads-

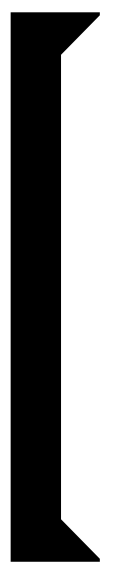

¿Quéehubo de realizaciones prácticas derivadas de aquella nutrida importación teórica del 'páis de Goethe'? En el plano metodológico concreto, el que prescribe pautas y actividades meridianamente claras para el maesstro, más bien poco.

criben, sin más, dos «pedagogías» a los bandos que combatieron en el pasado: nazismo y fascismo por un lado frente a demócratas liberales y socialistas por otro. Como si fueran sustancias inmiscibles. Pero no es así. Si en el pensamiento político, religioso, social, etc., las diferencias estuvieron tan marcadas como para servir de coartada a los que agredieron con las armas y provocaron dos terribles guerras, en el terreno pedagógico la línea divisoria no es nada clara. Del movimiento escolar reformista y de una mezcolanza filosófico-pedagógica contradictoria se alimentaron todos. Tanto los que se deslizaron hacia el fascismo o el nazismo como los que ocuparon las filas de las respectivas resistencias, compartían similares propuestas metodológicas (Mainer 2009:493; Mateos 2011). Y en cuanto al pensamiento sobre la escuela y sus funciones, de uno y otro lado se cultivaban discursos igualmente ilusorios, igualmente idealistas, igualmente carentes de razón crítica. Otra cosa es que en el nacional-catolicismo español y durante el dominio del nacionalsocialismo en Alemania se desplegase una pomposa retórica oficial que infectaba la educación emitiendo una sistemática condena de casi todo lo precedente. Para ilustrar con una pincelada esta tesis — que, lógicamente, exige un mayor desarrollo- veamos cómo en los tiempos que ahora rememoramos, sus protagonistas no clasificaban, como ahora se hace, en función de un supuesto isomorfismo entre las banderas ideológicas y las pedagógicas.

Luzuriaga, paradigma del proyecto liberal-socialista, fue introductor en España de Ernst Krieck, considerado como el pedagogo orgánico del nazismo. Es más: después de las guerras española y mundial, estando ya Luzuriaga exiliado en Argentina y sabiendo que "pasó lo que pasó», volvió a publicar en
$1966^{15}$, en la editorial Losada la obra de Krieck Bosquejo de la ciencia de la educación. Al mismo tiempo traducía al polémico G. Wineken, cuyas propuestas bien podrían ubicarse en tradiciones libertarias, o fuertemente influenciadas por Nietzsche e incluso por el mismo Krieck. Por tanto, en el terreno de las ideas pedagógicas hacer clasificaciones ajustadas a esquemas políticos preestablecidos no es lo más recomendable.

\section{Repercusiones en las prácticas escolares}

¿Qué hubo de realizaciones prácticas derivadas de aquella nutrida importación teórica del 'país de Goethe'? En el plano metodológico concreto, el que prescribe pautas y actividades meridianamente claras para el maestro, más bien poco. En ese sentido no hubo un educador alemán que obtuviera la resonancia del belga O. Decroly (cuyo método al menos se intentó...) o el éxito del francés C. Freinet. Lo más frecuente es que de las ideas a las aulas haya un oscuro trayecto con procesos de filtrado,

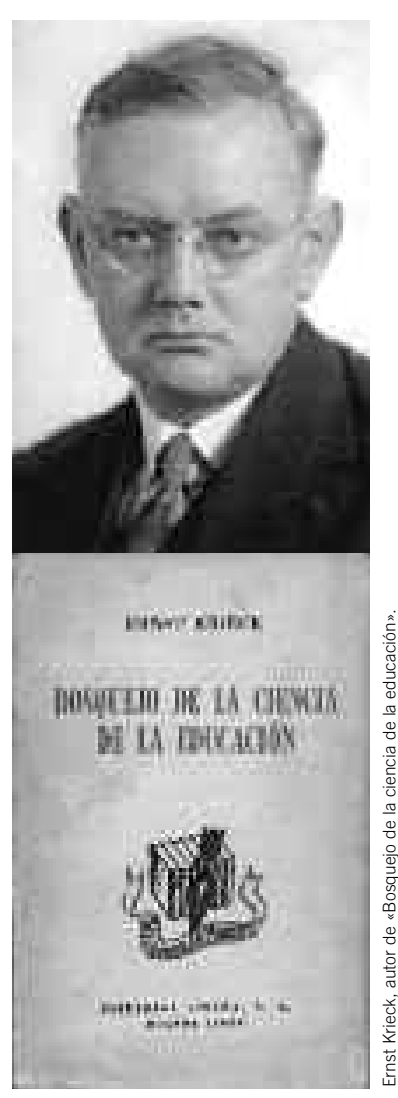
decantación y recontextualización a manos de distintos mediadores. La transformación (por seguir con las metáforas de laboratorio químico) se debe también a operaciones de mezclado. Veamos un ejemplo. La pedagogía del entorno a la que me refería al comienzo del artículo, es una mezcla de ideas, propuestas y principios que proceden de una buena parte de los pedagogos que venimos citando. No importa que la Heimatkunde, como programa y experiencia real en Alemania tenga como promotor a quien impartiera enseñanza en la ciudad de Weinheim y escribiera su método para la enseñanza de la $\mathrm{Hei}$ matkunde (Finger 1893). El mismo Finger no hizo otra cosa que desarrollar lo que ya, a mediados del siglo XIX, estaba en el ambiente, en una tradición que hundía sus raíces en Comenio. En realidad las ideas pedagógicas se repiten en unos y en otros, son maleables, emigran y se disuelven en consensos infraconscientes. De vez en cuando se forma un conglomerado de ideas y experiencias que se universaliza, y este es el caso de la didáctica del medio o entorno que proviene especialmente de Alemania. España tiene sus mediadores y publicistas para esa tradición: desde Rufino Blanco, Rodolfo Llopis, Pedro Chico, Adolfo Maíllo y un largo etcétera de pedagogos de toda laya político-ideológica, a los movimientos de renovación pedagógica de los años setenta y ochenta del pasado siglo que «reinventan» la vetusta tradición como si fuera lo más novedoso del mundo. Me refiero, claro está, al Grupo Rosa Sensat de Cataluña, al grupo Clarión de Aragón, al MCEP 
de ámbito nacional, etc. ¿Necesitó alguno de estos o los mismos diseñadores del área de Conocimiento del Medio (LOGSE, 1990) leer a Finger o a cualquiera de los pedagogos alemanes implicados en la tradición discursiva del medio como motivo de enseñanza? Desde luego que no. Por tanto las huellas del pensamiento pedagógico alemán han de rastrearse a través de laberínticos conductos.

Posiblemente el concepto de escuela unificada que acuñara Luzuriaga (a partir del alemán Einheitsschule), y el de escuela activa o del trabajo fueron los más estimados en España. Para el segundo conocimos aisladas aplicaciones en los momentos más entusiastas de la educación española y en cuanto a la vieja - y recurrentemente «inventada»- idea de la escuela unificada (o escuela única en versión francesa más radical, aunque hoy se usa el término inglés comprehensiva), nunca se llevó a la práctica, ni aún en la II República. Hubo de esperar a la educación tecnocrática de masas (a partir de 1970) para que las condiciones económicas y sociales del país, así como la imparable demanda educativa diesen cumplimiento a esa idea básica de origen alemán.

\section{La tardía aparición de las escuelas Waldorf en España}

Para terminar, dado que este número de Magazin se publica con motivo conmemorativo de $\mathrm{Ru}$ dolf Steiner, dedicaré unas líneas a las escuelas Waldorf en España. En este país la primera

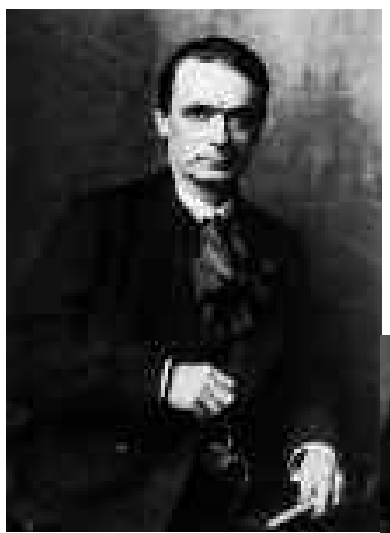
escuela seguidora de la pedagogía de Steiner ha sido la Escuela Libre Micael, creada en 1979, en las Rozas (Madrid). Desde entonces otras instituciones de iniciativa privada han ido ampliando la presencia del peculiar modelo educativo liberal inspirado en el credo antroposófico. Ya la participación de la Asociación Waldorf hispana aclarará, oportunamente, en este mismo número, la génesis y experiencia de sus escuelas. Por ello me limitaré, a dar alguna explicación histórica sobre su tardía, pero contundente, aparición en la escena escolar española.

Posiblemente es en el ya citado Diccionario de Pedagogía Labor (1936) donde aparecen por primera vez, en voces distintas, R. Steiner y su pedagogía antroposófica. Tanto uno como otra se presentan con tintes poco favorables, con distancia, e incluso, hostilidad. Allí se habla de "Cuan demoledora tiene que ser la acción de la educación antroposófica desde el punto de vista religioso,...» pues, los seguidores de Steiner se niegan a «educar al niño en los símbolos de la fe». He ahí por qué para el nacional-catolicismo, el modelo de la Escuela Waldorf y el esotérico sustrato religioso que dice inspirar sus principios educativos será de todo punto inaceptable. El odio del régimen a la masonería o cualquier heterodoxia no dejaría la mínima posibilidad de creación de una escuela de aquel tipo, que además era muy liberal. Si en la Alemania hitleriana se prohibieron las escuelas Waldorf, en la España franquista no habría ini-

ciativa que se atreviese ni a pensar en una escuela antroposófica. Y, en tiempos de la República los espacios de iniciativa privada que hubieran podido dar lugar a escuelas Waldorf (de corta trayectoria en aquel tiempo), digamos que estaban ocupados por la ILE o por escuelas de organizaciones obreras (socialistas o libertarias). Esas son explicaciones muy razonables para la tardía recepción en España de las instituciones de Steiner que solo aparecieron tras la recuperación de la democracia en España. Además, a finales de los setenta emergen nuevos patrones sociológicos que sitúan, cada vez más, a la educación en el

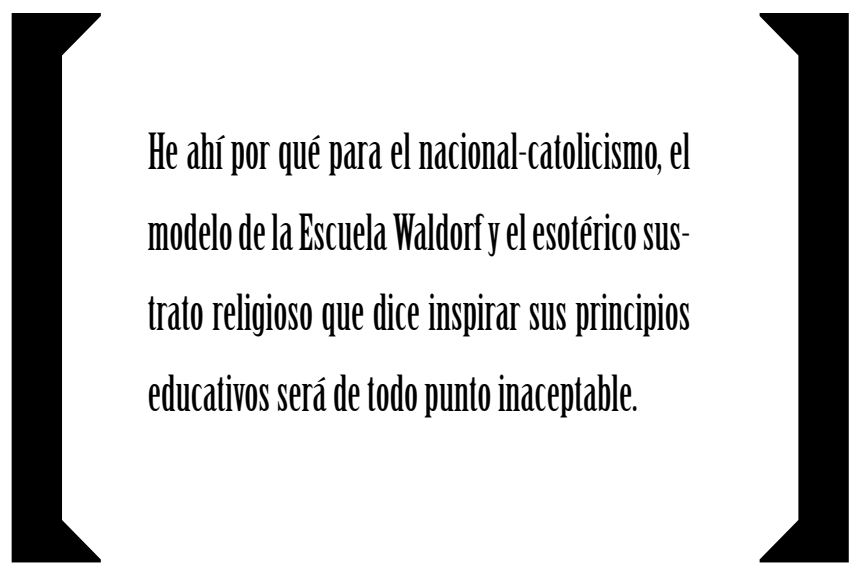

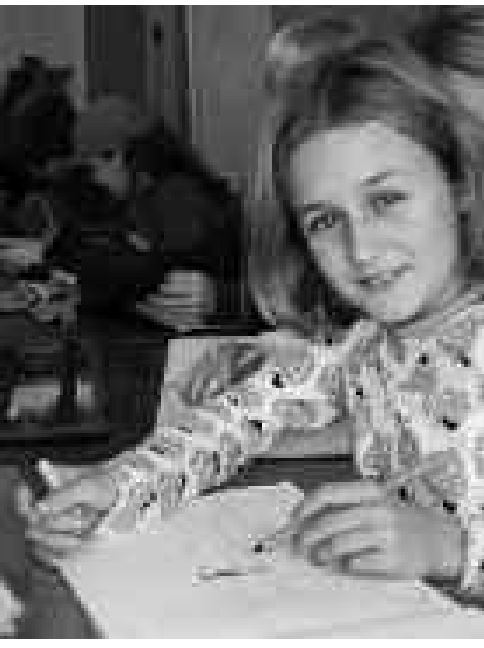

Sencilla y brevemente expuesta, tal es mi hipótesis explicativa de conclusión a este comentario final. A falta de discusión sobre su acierto, es incontrovertible que el nada desdeñable éxito de esta tardía importación pedagógica no se debe a propaganda o conocimiento previo en la cultura científica o burocrática de la escuela. Se produce, en fin, totalmente al margen de los pedagogos españoles, al margen de instancias oficiales o de reconocibles y evidentes think tanks. Lo cual nos hace sospechar (aún más) que los caminos y posible eficacia de la influencia pedagógica de Alemania en España (pero también de otros países) son imprevisibles; que no hay procesos lineales y establecidos, sino que todo depende de las variables y complejas circunstancias que perpetúan y cambian las relaciones de poder en las políticas de la cultura. 


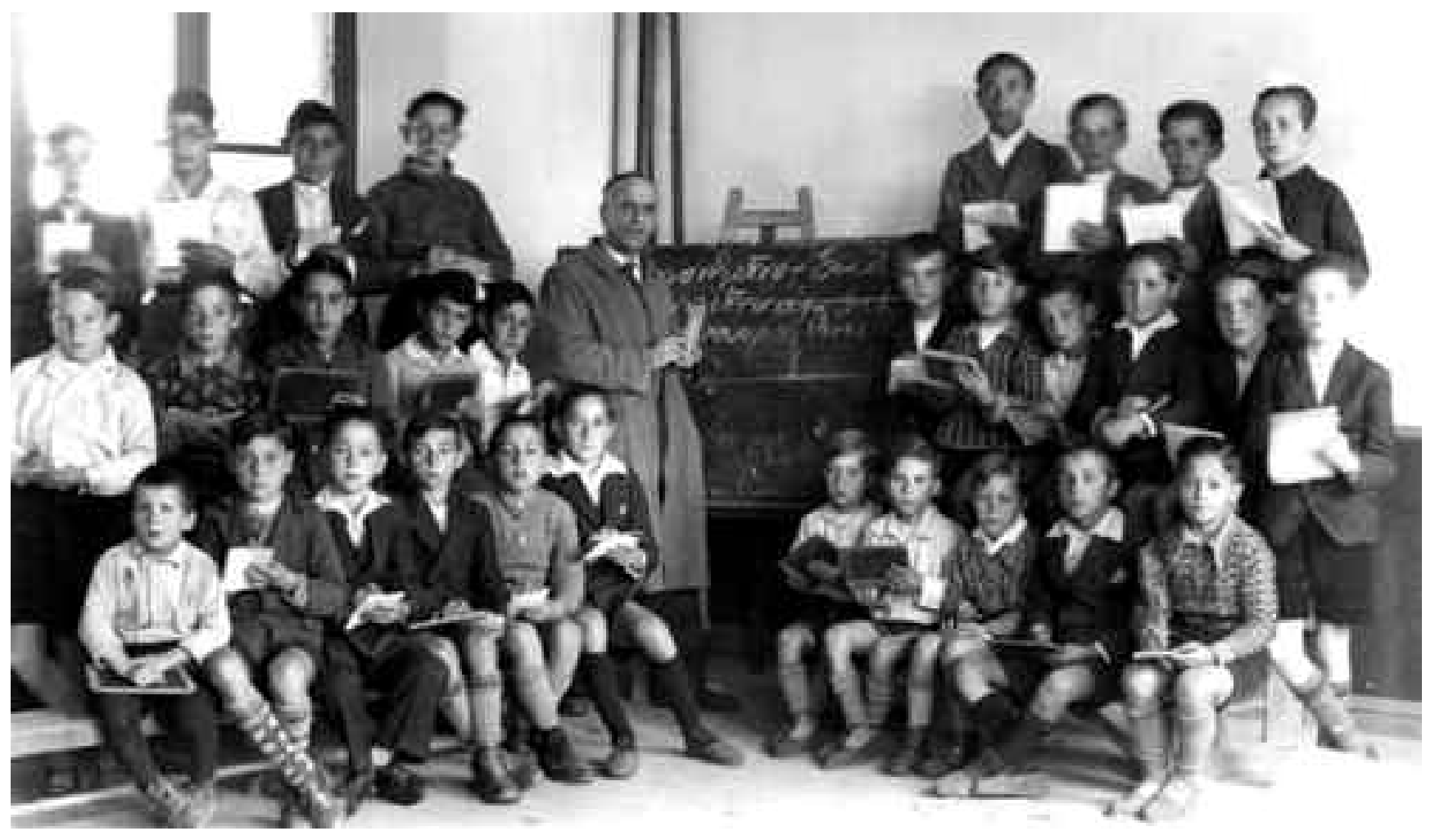

Referencias bibliográficas

Carderera, M. (1854): Diccionario de educación y métodos de enseñan$z a$, Tomo I. Imprenta de A. Vicente, Madrid.

Carderera, M. (1856): Texto de la voz "Intuitiva (plan de enseñanza)", firmado por Schwartz. Diccionario de Educación y Métodos de Enseñan$z a$, Tomo III, 201-210. Imprenta de A. Vicente, Madrid.

Colmenar, C. (1989): "La mujer como educadora de párvulos. La formación de maestras en el método educativo de Fröbel en España”, en $R e$ vista de Educación (290), 135-160.

Fichte, J. G. (1899): Discursos á la nación alemana: regeneración y educación en la Alemania moderna. (Prólogo y traducción de R. Altamira). La España Moderna, Imprenta de Idama Moreno, Madrid.

Finger, F. A. (1893): Anweisung zum Unterricht in der Heimatkunde. (Siebenten Auslage herausgegeben von Heinrich Makat). Weidmannsche Buchhandlung, Berlin.

Hera, J. de la (2002): La política cultural de Alemania en España en el periodo de entreguerras, CSIC, Madrid.

Hernández, J. M. (coord.) (2009): Influencias alemanas en la educación española e iberoamericana (1809. 2009), Globalia Ediciones Anthema, Salamanca.

Malagón, A. (1984): La «escuela Waldorf»: Un ejemplo de participación, en Cuadernos de Pedagogía (113), 61-65.

Mainer, J. (2009): La forja de un campo profesional. Pedagogía y didáctica de las ciencias sociales en España (1900-1970), CSIC, Madrid.
Mateos, J. (2008): La construcción del código pedagógico del entorno. Genealogía de un saber escolar, tesis doctoral inédita, director Dr. José María Hernández, Facultad de Educación de la Universidad de Salamanca.

Mateos, J. (2011): Genealogía de un saber escolar: la pedagogía del entorno, Octaedro, Barcelona.

Marín Eced, T. (1990): La renovación pedagógica en España (1907-1936): los pensionados en pedagogía por la JAE. CSIC, Madrid.

Mérida-Nicolich, E. (1983): Índice de la Revista de Pedagogía (1922-1936). Análisis de contenido. EUNSA, Pamplona.

Molero, A. (2001): Tradición y modernidad: la renovación pedagógica escolar, en Pedro Álvarez (dir.), Cien años de educación en España, BBVA/MECD, Madrid.

\section{Notas}

1. Se vienen celebrando congresos in ternacionales en la Universidad de Salamanca sobre la proyección educativa en España de distintos paí ses. Los materiales del dedicado a Alemania pueden consultarse en Hernández (2009).

2. La traducción al español fue de Rafael Altamira, insigne historiador y pedagogo, amigo de la Institución Libre de Enseñanza (ILE) e influyente personaje en la política educativa.

3. Lo que he llamado código pedagó gico del entorno en una tesis de doctorado (Mateos 2008). De más fácil acceso y asequible lectura la investigación ha sido resumida muy recientemente (Mateos 2011).
4. ¿No ha sido eso mismo lo que ha ocurrido con la escuela Waldorf, teniendo en cuenta sus orígenes en la escuela montada para hijos de empleados de la fábrica de cigarrillos Waldorf Astoria, en Stuttgart?

5. He de señalar una circunstancia que pesa como elemento diferenciador entre España y los países donde domina la herencia luterana. En estos últimos las relaciones entre Iglesia y Estado, al menos en los que se refiere a la educación, han sido mucho más fáciles, más distendidas, más independientes. En España, el "pasado que pesa" para un país que ha tenido "mucha Iglesia y poco Estado" ha sido asfixiante.

6. A modo de ejemplo puede citarse un programa firmado por Schwartz, de sorprendente actualidad, bajo la voz de "Intuitiva (plan de enseñanza)" (Carderera, 1856).

7. Fue en el Congreso Nacional Pedagógico de 1882 donde se escenifica dicha confrontación, suculenta e ilustrativa según las fieles actas de sus sesiones.

8. Seguramente fue en la Escuela de Institutrices donde se llevó a cabo, en 1873, la primera clase de Pedagogía Especial según el sistema Fröbel. El profesor, claro está, no era otro que Pedro de Alcántara García.

9. Así la obra más importante de Herbart, la Pedagogía general derivada del fin de la educación, fue traducida al español por Lorenzo Luzuriaga y editada en 1919, con un enjundioso prólogo de Ortega.

10. Marín Eced (1990) da el escaso número de cuarenta y dos pensionados en Alemania. Sin embargo de otros campos científicos el número fue considerable. Para una visión amplia de la proyección cultural alemana en España durante el periodo entre guerras puede verse Hera (2002).

11. El término fue inventado por Lorenzo Luzuriaga cuando reseñaba las obras completas de Ortega y Gasset. En la nómina de esa "generación”, y limitándonos al campo de la pedagogía, se ha incluido a Lorenzo Luzuriaga, a su mujer $\mathrm{M}^{\mathrm{a}}$ Luisa Navarro, a Manuel García Morente, a María de Maeztu, a Domingo Barnés, a Luis de Zulueta (este llegó a ser embajador de España en Berlín), a José Castillejo, a Fernando de los Ríos, ... Y por supuesto al mismo Ortega que en Pedagogía, para algunos, fue una primera autoridad.

12. Fue el artífice del programa educativo del PSOE. Participó activamente en la política educativa de la Segunda República española, cuyo programa escolar (escuela única, activa, pública y laica) fue resultado de una lucha larga y tenaz que llevó consigo un profundo sentido de renovación política y técnica de la educación como sistema y de la metodología y los instrumentos al servicio de los educadores.

13. Sobre la Revista de Pedagogía véase (Mérida-Nicolich, 1983).

14. No en vano la editorial fue fundada en 1915 por el alemán Georg Pfleger Hoffman, refugiado en Barcelona tras la Primera Guerra Mundial.

15. La primera vez fue 1928 , en $\mathrm{Pu}$ blicaciones de la Revista e Pedagogía. 